\title{
Dipeptidase activity in the small intestinal mucosa during pregnancy and lactation in the rat
}

\author{
By B. A. ROLLS \\ National Institute for Research in Dairying, Shinfield, Reading $R G 2{ }_{9} A T$
}

(Received 15 June 1973 - Accepted 23 August 1973)

\begin{abstract}
I. Rats were mated and at weekly intervals during pregnancy and lactation, and after weaning, the dipeptidase activity in the supernatant fraction from small intestinal mucosa extracts was determined for two dipeptides: glycyl-L-leucine dipeptidase $(E C$ 3.4.3.2) and L-alanyl-L-glutamic acid dipeptidase.

2. Dipeptidase activity is found mainly in the soluble (supernantant) fraction of the mucosa homogenate.

3. Compared with those values obtained for unmated controls, the food consumption of the animals and the nitrogen content, total and specific activities of the dipeptidases (per unit quantity of $N$ ) in the soluble fraction of the small intestinal mucosa extracts increased slightly during pregnancy and markedly during lactation. After the pups were weaned, values for all these measurements fell rapidly.

4. Whether the increases found in enzyme activity were simply a response to increased food intake or were the result of hormonal stimulus is discussed.
\end{abstract}

Although the first stages of protein digestion have been established, relatively little is known of the final stage, the digestion of peptides by peptidases and the absorption of amino acids. Whether amino acid or peptide uptake is quantitatively the more important is not clearly understood. There is evidence that the activities of pancreatic enzymes can be modified by changes in the diet (Snook \& Meyer, 1966) and Solimano, Burgess \& Levin ( 1967 ) obtained results which suggested that rats given a low-protein or protein-free diet had lower intestinal dipeptidase activities than those given a normal diet, although, perhaps due to the small numbers of animals used, their results were statistically significant in only one instance. Dipeptidases are located largely within the wall of the small intestine and are important in this final stage of protein digestion (Lindberg, I966; Matthews, Lis, Cheng \& Crampton, 1969; Peters, I970a).

The food intake of the rat increases slightly during pregnancy and considerably during lactation. It is known that the small intestine increases in length, weight and intestinal surface area during pregnancy and lactation (Craft, 1970; Fell, 1972). The finding of Campbell \& Fell (1964) that the digestibility of the ingested crude protein did not change during lactation suggests that there is an increase in total digestive and absorptive capacity of the intestine even though there is a decrease in absorptive ability per unit weight or per unit area of mucosa (Craft, 1970). To determine whether the increased consumption of food, and hence of protein, was accompanied by an increase in the ability of the gut to digest and absorb protein, dipeptidase activities of the supernatant fraction from small intestinal mucosa extracts were determined for groups of rats at different stages of pregnancy and lactation, and after weaning. 


\section{EXPERIMENT AL}

\section{Materials}

The peptides glycyl-L-leucine and L-alanyl-L-glutamic acid were obtained from Cyclo Chemical, Los Angeles, California, USA. The other chemicals used were obtained from British Drug Houses Ltd, Poole, Dorset.

\section{Tests with rats}

Hooded Norwegian female rats, 3-4 months old and weighing $230-250 \mathrm{~g}$, from the Institute colony, were used. Vaginal smears were examined to detect the stage of oestrus so that mating could be timed. Subsequently, the presence of spermatozoa in the vaginal smear was taken to indicate impregnation. That the animals were pregnant was checked by inspection of the uterus by dissection at the end of the experiment. Controls were unmated animals from the same litters; litter-mates were distributed randomly among the experimental groups.

The rats were given a stock laboratory diet (autoclaved Spillers' Small Animal Diet). For measurements of food consumption, rats were caged individually throughout the experimental period. Otherwise they were housed in groups of three until the and week of pregnancy and thereafter, singly. All animals were allowed unrestricted access to food and water.

Animals were taken at selected intervals during the course of pregnancy and lactation, and after weaning, at the same time of day, without prior starvation. The rats were anaesthetized with diethyl ether and the gut was exposed. The small intestine was ligated at the pylorus and cannulated just distal to this point. The ileal end was transected at the junction with the caecum and the small intestine was washed out with the minimum quantity of cold $\mathrm{NaCl}$ solution $(9 \mathrm{~g} / \mathrm{l})$. The entire small intestine was then removed and cooled on ice, and the rats were killed. Adhering fat was removed and the intestine was kept cool on ice and cut lengthwise and the mucosa removed by gentle scraping with a glass slide. The mucosa was homogenized with icecold $\mathrm{O} \cdot \mathrm{I} \mathrm{M}-\mathrm{NaCl}$ using an all-glass pestle and mortar and the total volume was made up to about $90 \mathrm{ml}$. The extract was prepared by stirring the homogenate for $30 \mathrm{~min}$ in an ice-bath and centrifuging the homogenate for $20 \mathrm{~min}$ at $17000 \mathrm{~g}$ using an MSE $\mathrm{I} 8$ centrifuge (Measuring and Scientific Equipment Ltd, London SW I). Portions of the supernatant fraction obtained were used, after appropriate dilution with saline $(9 \mathrm{~g}$ $\mathrm{NaCl} / 1$ ), for determination of enzyme activity and for nitrogen determination using the micro-Kjeldahl method.

The dipeptidase (glycyl-L-leucine dipeptidase $(E C \quad 3 \cdot 4 \cdot 3 \cdot 2)$ and L-alanyl-Lglutamic acid dipeptidase) activities of the freshly prepared supernatant fractions were estimated immediately using the spectrophotometric technique of Josefsson \& Lindberg (I965). Portions of diluted mucosa-extract supernatant fraction $(0.05 \mathrm{ml})$ were incubated with $0.1 \mathrm{ml} \mathrm{O.I} \mathrm{M-phosphate} \mathrm{buffer,} \mathrm{pH} 7.4$, and $0.05 \mathrm{ml} 0.03 \mathrm{M}$-dipeptide solution at $37^{\circ}$. The reaction was terminated at 0,5 and ro min by the addition of $\mathrm{I} \cdot 3 \mathrm{ml}$ absolute ethanol, the dilution of the mucosa-extract supernatant fraction being arranged to ensure a linear reaction course over this period. After centrifugation to 
remove precipitated protein, the dipeptide concentration in the reaction medium was estimated from the extinction value at $220 \mathrm{~nm}$. Each assay was done in quadruplicate and for each dipeptidase two assays were done at $0.5 \mathrm{~h}$ intervals. The $\mathrm{pH}$ of $7 \cdot 4$ was chosen as it is close to the $\mathrm{pH}$ of the intestinal tissue and to the observed $\mathrm{pH}$ for maximum dipeptidase activity (Josefsson \& Lindberg, I965).

To estimate the response of the animal as a whole it was considered essential to use the entire length of the small intestine. As the dipeptidase activity varies considerably along the length of the small intestine (Josefsson \& Lindberg, 1966) and its total length and weight change during pregnancy and lactation (Cripps, I972; Fell, 1972), any estimate based on unit weight or length would be misleading.

Estimates of the dipeptidase activity in the unmated control animals were done at intervals throughout the experimental period. All solutions used in the enzyme assay were replaced at least every $\mathrm{I}_{4} \mathrm{~d}$.

\section{RESULTS}

The dipeptidase activities in the mucosa-extract supernatant fraction, expressed as percentages of those in the mucosa-homogenate extract, were (mean $\pm \mathrm{sE}$ ) $87 \cdot \mathrm{r} \pm 3 \cdot 4$ and $96 \cdot \mathrm{I} \pm 3.7$ for glycyl-L-leucine and L-alanyl-L-glutamic acid dipeptidases respectively, and these values were unaffected by the physiological state of the animals. Once extracted, the dipeptidases were highly unstable even in the cold (cf. Das \& Radhakrishnan, I972) and activities began to decay within 3-4 h. The results of duplicate assays that did not agree were rejected.

After the Ist week of pregnancy the food consumption of mated animals was always greater than that of unmated animals (Fig. I $c$ ). The highest food intake was recorded in the $3^{\text {rd }}$ week of lactation, and after weaning the consumption returned rapidly to normal. This pattern of food intake is consistent with that previously reported for the rat (Anderson \& Turner, I963; Crean \& Rumsey, I971; Cripps, 1972).

The $\mathrm{N}$ content (which was used as a measure of the protein content) and the total dipeptidase activities in the supernatant fractions of the mucosa extracts are shown in Fig. $\mathrm{I} d$, and $a$ and $b$ respectively. The unit of dipeptidase activity is that defined by Lindberg (1966). During pregnancy there were slight or moderate increases in the values for all these measurements, and during lactation there were striking increases, the maximum values being found at the end of the and week of lactation, when there were increases of over $200 \%$ in dipeptidase activities. After weaning, the values for the enzyme activities returned essentially to the control values within 2 weeks; in contrast the $\mathrm{N}$ content remained rather higher than the control value.

The total and specific dipeptidase activities increased during pregnancy and lactation (Fig. I $e$ and $f$ ). Once again, the maximum values were recorded at the end of the 2 nd week of lactation. The specific activities 2 weeks after weaning were lower than those found in unmated animals.

Among the rats used, there was a group of six that failed to feed their pups. The total L-alanyl-L-glutamic acid dipeptidase activity of the supernatant fraction from small intestinal mucosa extracts of these animals was estimated at what would have been the end of the 2 nd week of lactation and was found to be (mean $\pm \mathrm{SE}$ ) 


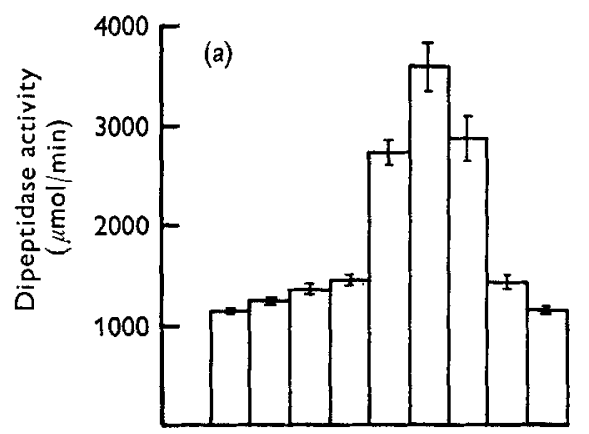

$[(b)$

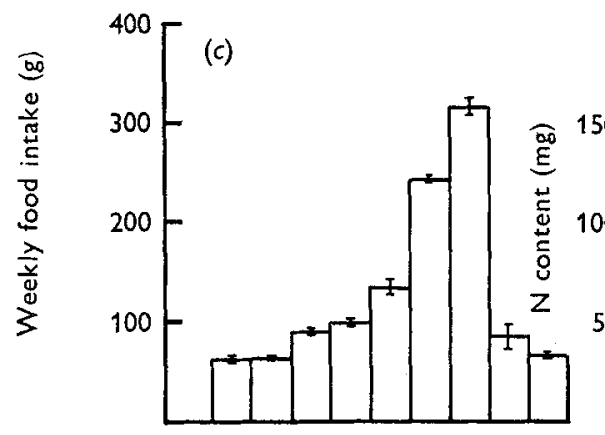

(d)
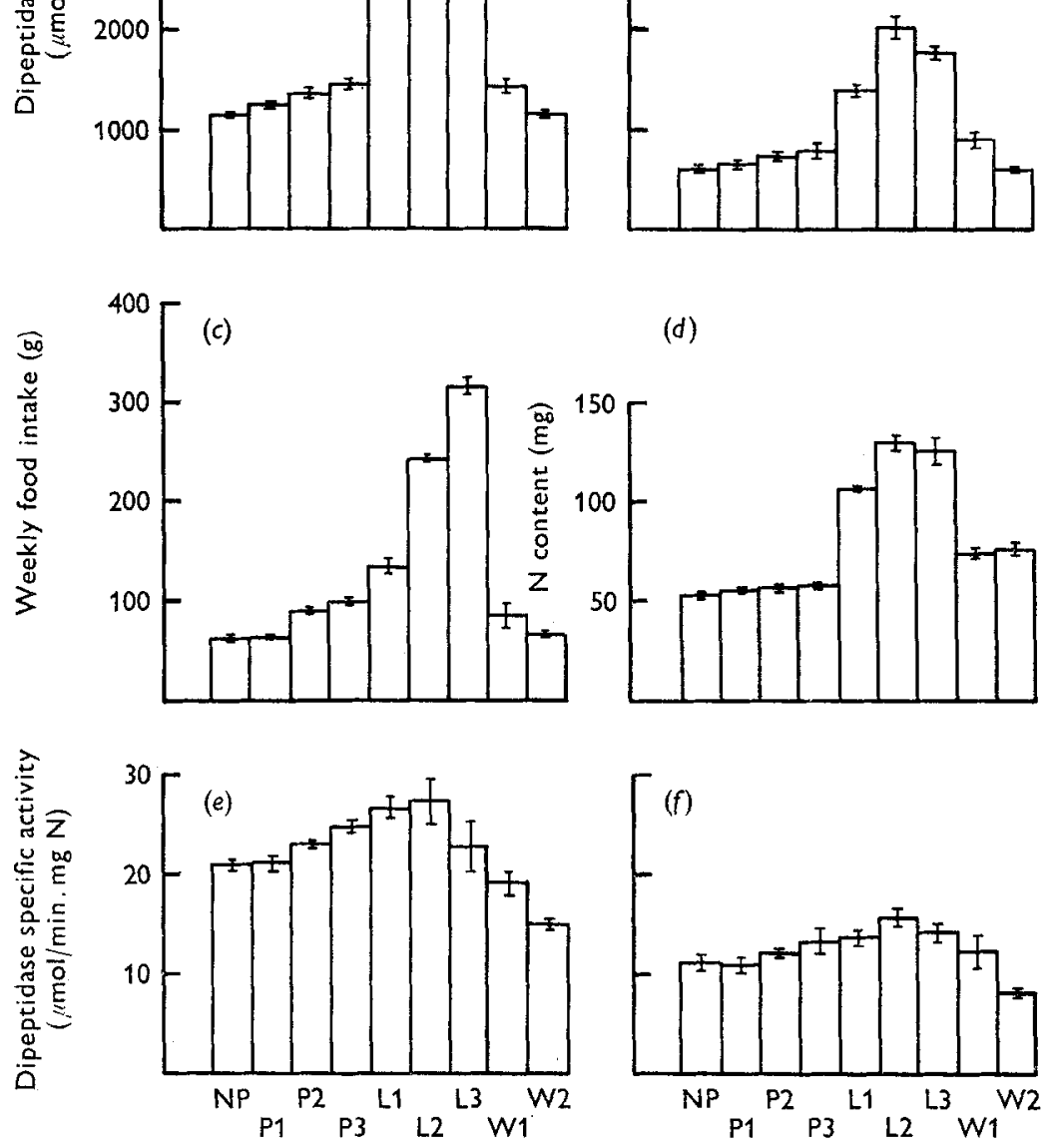

Physiological state

Fig. I. Total ( $a$ and $b$ ) and specific ( $e$ and $f$ ) activities of glycyl-L-leucine dipeptidase (EC $3 \cdot 4 \cdot 3 \cdot 2)$ and L-alanyl-L-glutamic acid dipeptidase respectively, and total nitrogen contents $(d)$ in the supernatant fractions from extracts of the small intestinal mucosa of groups of rats. Mean values with their standard errors (represented by vertical bars) for groups of six rats at the end of the Ist, 2nd and 3 rd weeks of pregnancy ( $P_{1}, P_{2}$ and $P_{3}$ ), at the end of the rst, and and 3 rd weeks of lactation $\left(L_{I}, L_{2}\right.$ and $\left.L_{3}\right)$ and at the end of the Ist and and weeks after weaning (WI and $W_{2}$ ), together with the corresponding values for a group of fourteen unmated littermate controls (NP). The mean values with their standard errors (represented by vertical bars) for the weekly food intakes $(c)$ for a group of five rats during pregnancy and lactation, and after weaning, are shown, together with the mean weekly food intake over the same period for a group of five unmated litter-mate controls. The unit of dipeptidase activity is that defined by Lindberg ( 1966$)$. 
Vol. 33

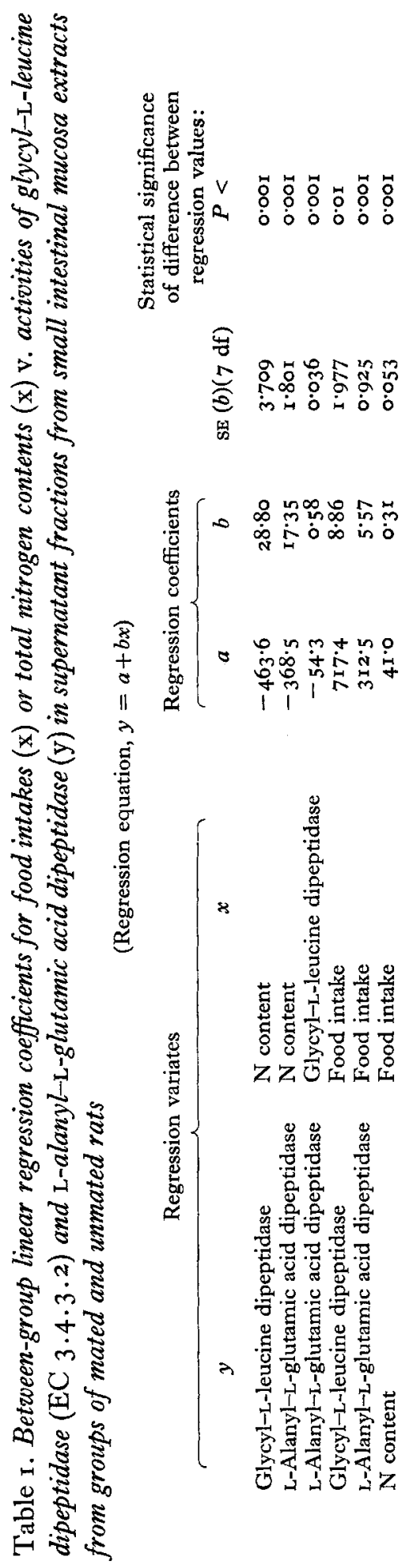


Table 2. Between-group multiple regression coefficients for dipeptidase activities (y) v. nitrogen content $\left(\mathrm{x}_{1}\right)$ of the supernatant fractions from small intestinal mucosa extracts and food intake $\left(\mathrm{x}_{2}\right)$ for groups of mated and unmated rats

(Regression equation, $y=a+b_{1} x_{1}+b_{2} x_{2}$ )

\begin{tabular}{|c|c|c|c|c|c|c|c|}
\hline Enzyme & $\mathrm{df}$ & $b_{1}$ & $\mathrm{SE}\left(b_{1}\right)$ & $\begin{array}{c}\text { Statistical } \\
\text { significance } \\
\text { of difference } \\
\text { between } \\
\text { regression } \\
\text { values } \\
P<\end{array}$ & $\begin{array}{l}\text { e } \\
\text { e }\end{array}$ & $\begin{array}{r}\mathrm{s} \\
\mathrm{o} \\
\operatorname{SE}\left(b_{2}\right)\end{array}$ & $\begin{array}{c}\text { Statistical } \\
\text { significance } \\
\text { of difference } \\
\text { between } \\
\text { regression } \\
\text { values }\end{array}$ \\
\hline $\begin{array}{l}\text { Glycyl-L-leucine } \\
\text { dipeptidase }(E C, 3 \cdot 4 \cdot 3,2)\end{array}$ & 6 & 28.75 & 9.627 & 0.05 & 0.019 & 3.254 & NS \\
\hline $\begin{array}{l}\text { L-Alanyl-L-glutamic } \\
\text { acid dipeptidase }\end{array}$ & 6 & 13.69 & 4.377 & 0.05 & I.359 & I. 479 & NS \\
\hline
\end{tabular}

$54 \mathrm{I} \pm$ IOI $\mu \mathrm{mol} / \mathrm{min}$, a value close to that of the controls. Their food consumption was also similar to (but slightly lower than) that of the controls.

The between-group linear regressions between enzyme activity, $\mathrm{N}$ content and food intake were all highly significant $(P<0.001)$, except for glycyl-L-leucine dipeptidase activity $v$. food intake $(P<0.01)$ (Table $\mathrm{I})$. The between-group multiple regressions of enzyme activity $v$. N content of the supernatant fraction from the mucosa extract and the food intake (Table 2) were not significantly better than the linear regressions for enzyme activity $v$. $\mathrm{N}$ content only, suggesting that the relationship between enzyme activity and $\mathrm{N}$ content was closer than that between enzyme activity and food intake. The relationship between enzyme activity and $\mathrm{N}$ content was investigated further by calculating the within-group linear regressions (Table 3, Fig. 2). These relationships were significant $(P<0.05)$ only for glycyl-L-leucine dipeptidase in the 2nd week of pregnancy and the 2nd week of weaning, and nearly significant $(P<0 \cdot I)$ for this enzyme in the $3^{\text {rd }}$ week of pregnancy and for L-alanyl-L-glutamic acid dipeptidase in the and week of pregnancy.

\section{DISCUSSION}

The presence of about $90 \%$ of the dipeptidase activity in the soluble fraction of the mucosa-homogenate extract is in agreement with other studies with rats (Robinson, 1963), guinea-pigs (Peters, 1970b) and pigs (Josefsson \& Sjöström, 1966). This is consistent with the location of the major portion of dipeptidase activity in the cytosol. The significance of the amount of the activity (up to $10 \%$ ) associated with the brush border has been discussed by Fujita, Parsons \& Wojnarowska (1972).

The results presented here suggest that the enzymes capable of hydrolysing certain dipeptides increased slightly during pregnancy and considerably during lactation. The same general pattern was reflected in the food intake, and on first inspection of these results it may seem that the gastrointestinal changes are a simple functional response to food intake. However, the maximum values for both total and specific 
Vol. 33

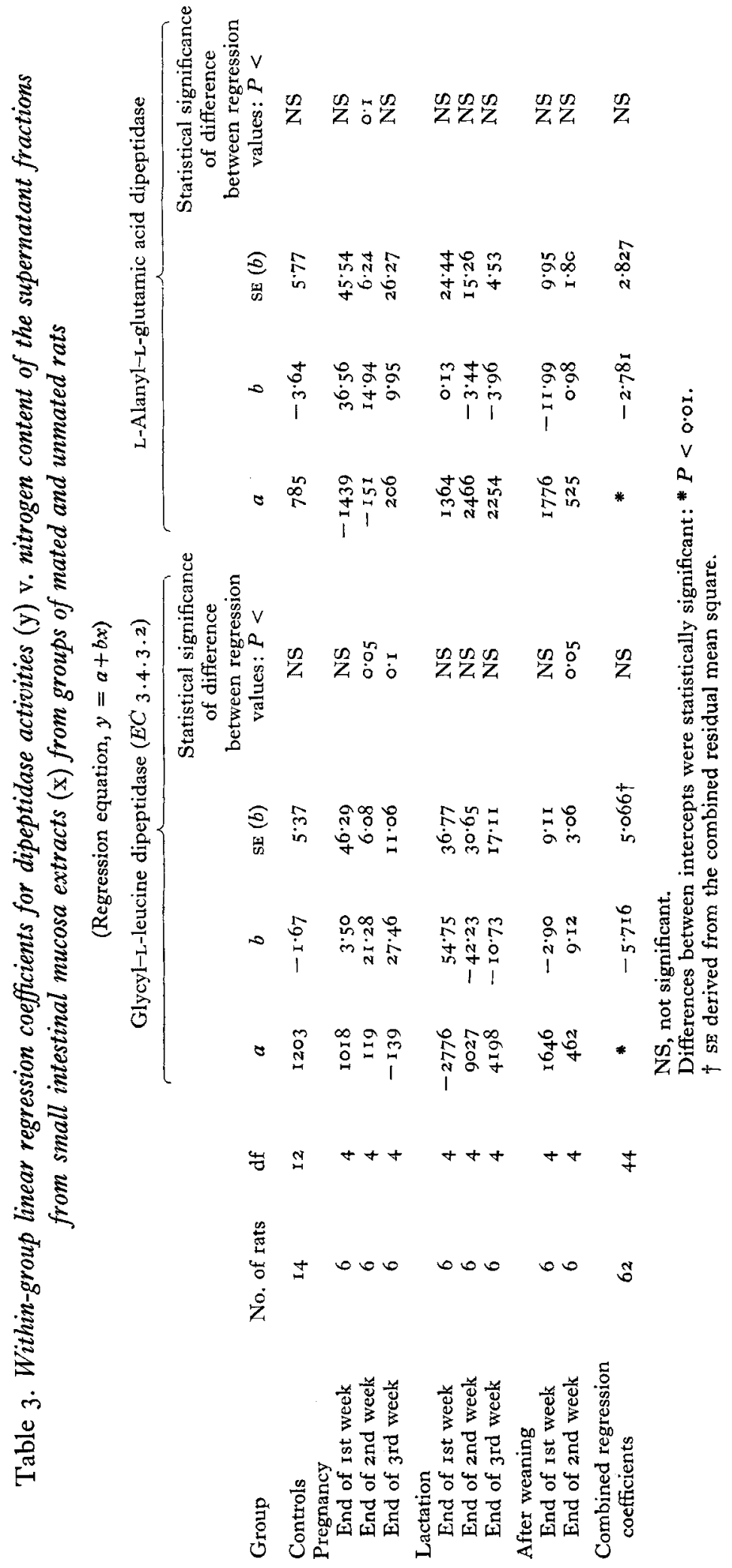




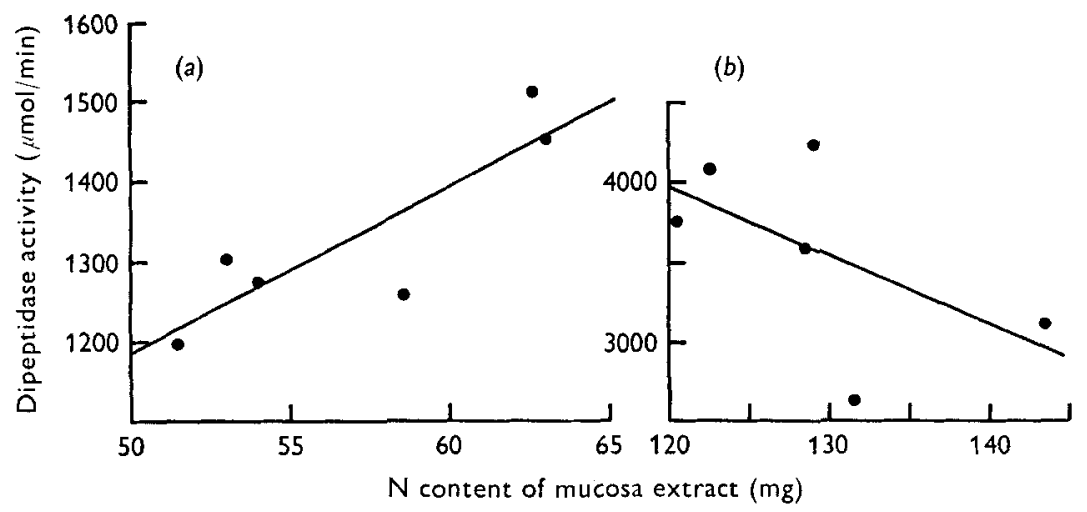

Fig. 2. Within-group linear regression for glycyl-L-leucine dipeptidase $(E C \quad 3 \cdot 4 \cdot 3 \cdot 2)$ activities $(y) v$. nitrogen content $(x)$ of supernatant fractions from small intestinal mucosa extracts; $(a)$ at the end of the 2nd week of pregnancy $(y=119+2 I \cdot 28 x ; P<0.05) ;(b)$ at the end of the and week of lactation $(y=9027-42 \cdot 23 x$; not significant) in groups of six rats. The unit of activity is that defined by Lindberg (1966).

dipeptidase activities were at mid-lactation, as were the maximum values for peptic and parietal cell populations (Crean \& Rumsey, 1971) and the total intestinal absorption of glucose and L-leucine (Cripps, 1972), whereas there is general agreement that food intake increases throughout lactation. Cripps (1972), who took particular care that the pups were denied access to the dams' food supply, did record a slight, although not significant, decrease in food intake in the final days of lactation.

Fell and his colleagues (Fell, 1972) concluded from considerable experimental evidence that hypertrophy of the alimentary tract is dependent on food intake, and results in the absorption of a constant proportion of the protein. Indeed, when the food intake of lactating rats was restricted, intestinal hypertrophy could be abolished (Campbell \& Fell, 1964).

The relationships between the food intake, the $\mathrm{N}$ contents and the dipeptidase activities (Table I) could be taken as support for this view, although it should be stressed that the maximum values did not occur at the same time and that the high degree of correlation is largely derived from the wide separation of the values for the unmated group and pregnant group and the lactating group. This is supported by the within-group regressions which were significant $(P<0.05)$ or nearly so $(P<0 . \mathrm{I})$ in only four instances out of eighteen and by the fact that the combined regressions for dipeptidase activities $v$. $\mathrm{N}$ content were not significant: it is not clear whether these measurements would have been shown to be correlated if more animals had been used in each group. As it is, the results must be judged inconclusive on this point.

Thus, it is possible that the cause could be hormonal and not necessarily related direct to food intake. However, Crean \& Rumsey (197r) pointed out that none of the hormones known to increase in pregnancy or lactation causes hypertrophy of the gastrointestinal tract. Nonetheless, it is possible that a stimulus, perhaps originating in the hypothalamus or adrenal cortex and possibly not directly connected with pregnancy, could increase food intake and, consequentially or concomitantly, lead to intestinal hypertrophy. The rapid loss of the increased dipeptidase activity in those 
animals that rejected their young could have been the result either of the lowered food intake or of an hormonal disturbance, or all these could be the manifestation of a cause as yet unknown. Cotes $\&$ Cross (1954) attributed the increased food intake of lactating rats to the act of suckling, since suckled dams that had had their galactophores cut ate more than those animals with their galactophores intact that were not suckled, but it is clear that this could not be responsible for the increase in food consumption in pregnancy.

The increases in specific activity of the dipeptidases suggest that the changes were not simple hyperplasia, but that the mucosa cells had adapted to the changed conditions. Moreover, after weaning there was a fall in specific activity, as there was in the absorption of leucine and glucose per unit length of intestine (Cripps, 1972). However, as the lengths of the small intestines of these post-weaning rats were greater than those of rats that had not been mated, the total absorptive and digestive capacities were maintained at approximately the values found in unmated animals.

Clearly there is a need for further work to establish any relationships between enzyme activity and food intake, and the work reported here is being extended to study other gastrointestinal enzymes responsible for digestion and absorption and the effects of varying the composition of the diet of the test animals.

I should like to thank Dr J. W. G. Porter and Mr D. R. Westgarth for their interest and advice, Mrs M. Payne for technical assistance and Miss M. Tyler and her staff for their care of the rats.

\section{REFERENCES}

Anderson, R. R. \& Turner, C. W. (I963). Proc. Soc. exp. Biol. Med. 1r3, 334.

Campbell, R. M. \& Fell, B. F. (1964). F. Physiol, Lond. 171, 90.

Cotes, P. M. \& Cross, B. A. (1954). F. Endocr. 10, 363 .

Craft, I. L. ( 1 970). Clin. Sci. 38, 287.

Crean, G. P. \& Rumsey, R. D. E. (1971). F. Physiol., Lond. 215, I8I.

Cripps, A. (I972). Gastrointestinal function during pregnancy and lactation in the rat. BSc Thesis, University of New England, Armidale, New South Wales, Australia.

Das, M. \& Radhakrishnan, A. N. (1972). Biochem. F. 128, 463.

Fell, B. F. (1972). Wld Rev. Nutr. Diet. 14, 180.

Fujita, M., Parsons, D. S. \& Wojnarowska, F. (1972). F. Physiol., Lond. 227, 377.

Josefsson, L. \& Lindberg, T. (1965). Biochim. biophys. Acta 105, 49.

Josefsson, L. \& Lindberg, T. (I066). Acta physiol. scand. 66, 4IO.

Josefsson, L. \& Sjöström, T. (r966). Acta physiol. scand. 67, 27.

Lindberg, T. (1 966). Acta physiol. scand. 69, Suppl. 285.

Matthews, D. M., Lis, M. T., Cheng, B. \& Crampton, R. F. (1969). Clin. Sci. 37, 75 I.

Peters, T. J. (I970a). Gut II, 720 .

Peters, T. J. (1970b). Biochem. F. 120, 195.

Robinson, G. B. (1963). Biochem. $\mathfrak{f} .88,162$.

Snook, J. T. \& Meyer, J.H. (1966). In The Role of the Gastrointestinal Tract in Protein Metabolism p. 97 [H. N. Munro, editor]. Oxford: Blackwell Scientific Publications.

Solimano, G., Burgess, E. A. \& Levin, B. (1967). Br. F. Nutr. 21, 55. 